\title{
Articulación geminada lateral en castellano medieval: el testimonio de los textos poéticos
}

\author{
Lateral geminate articulation in medieval Spanish: \\ the testimony of the versified texts
}

\author{
Francisco Pedro Pla Colomer \\ Universidad de Jaén \\ fpla@ujaen.es \\ ORCID iD: https://orcid.org/0000-0001-7121-8910
}

RESUMEN: El objetivo principal del presente estudio es la descripción del segmento geminado lateral en la historia de la lengua castellana en sus diferentes contextos fónicos: como reducto de -LL- latina y en sandhi externo o fonética sintáctica ([-1\#1-]). Para ello, se pretende abordar en las siguientes páginas el análisis de la rima de los poemas medievales que abarcan los primeros testimonios en lengua castellana hasta los compuestos en la corte de los Reyes Católicos, desde el convencimiento de que el análisis de los sonidos en situación de rima permite arrojar luz a la reconstrucción del componente fónico subyacente en las grafías.

Palabras clave: Historia de la lengua, fonética y fonología históricas, geminada lateral, poesía medieval, métrica.

ABSTRACT: The main goal of the current paper is the description of the lateral geminate segments in the History of the Spanish language: derived from the Latin -LL-, as well as those produced as a secondary process in external context of sandhi ([-1\#1-]). To achieve this aim we have analysed the rhymes of the medieval Spanish poetry from its origins until the court of the Catholic Kings, considering that the sounds of the rhymes can shed some light in the reconstruction of the language pronunciation, which underlies in its spelling.

Keywords: History of language, historical phonetic and phonology, lateral geminate segments, medieval poetry, metric. 


\section{INTRODUCCIÓN Y ESTADO DE LA CUESTIÓN}

Es bien sabido que la emergencia de los sonidos palatales de creación romance ha sido uno de los temas que han recibido mayor atención por parte de los especialistas en el ámbito de la fonética y fonología históricas. La publicación del Manual de gramática histórica española de Menéndez Pidal, corregido y aumentado hasta su sexta edición en 1941, supuso el establecimiento de los cimientos científicos en torno a la agrupación de los fenómenos de palatalización ordenados en un segmento cronológico de absoluto rigor según los efectos de la yod. A partir de ese momento, la nómina de investigadores que han dedicado atención especial a este fenómeno articulatorio es numerosa y fecunda, es el caso de las obras de Lapesa (1981), Amado Alonso (1969-1976 [1955]), Dámaso Alonso (1972 [1962]), Cano Aguilar (1988), Lloyd (1993), Penny (2006 [1993]), Ariza Viguera (1994, 2009 y 2012), Echenique Elizondo y Martínez Alcalde (2013) y Tuten, Pato y Schwarzwald (2016), entre otros muchos.

Una de las palatales que presentan mayor problema en cuanto a la descripción de su génesis y evolución es el sonido palatal lateral sonoro $[\Lambda]$ procedente de los segmentos latinos intervocálicos [-lj-, -k'l- y -g’l-] (yod segunda según Menéndez Pidal), iniciales [pl-, kl-, fl-] y de la geminada lateral latina [-1.1-]. La evolución de estos elementos desembocó en distintas soluciones que, en el caso de la lengua castellana, cristalizaron en el sonido velar fricativo $[\mathrm{x}](<[-\mathrm{jj}-$, -k'l- y -g'l-]) y el palatal lateral $[\Lambda](<$ [pl-, kl-, fl-] y [-1.1-]) o fricativo mediopalatal en las zonas de confusión o yeísmo, si bien es cierto que existió una etapa en que el resultado palatal lateral de estos procesos habría sido común.

Por el contrario, al margen de los estudios de Torreblanca (1982-1983), Pensado (1993) y más recientemente Espinosa Elorza (2014), no abundan las investigaciones centradas en la descripción de los elementos geminados en la historia de la lengua castellana y, más concretamente, en la posibilidad de que en época medieval existiera un sonido geminado lateral, reducto del segmento -LL- latino, objetivo principal del presente estudio ${ }^{1}$. Para ello, se parte de un breve análisis sobre los procesos de palatalización que resultaron en $[\Lambda]$ para dar paso al estudio de la geminada lateral a partir de un corpus poético, ya que el análisis de los sonidos en situación de rima permite arrojar luz a la reconstrucción del componente fónico subyacente en las grafías²; en tanto los versos castellanos medievales se midieron y rimaron tanto por imperativos poéticos como por las características lingüísticas de cada época en aras de la regularidad métrica.

\footnotetext{
${ }^{1}$ La defensa de una articulación geminada la desarrollé previamente en mi tesis doctoral Reconstrucción de la pronunciación castellana medieval: la voz de los poetas (tesis dirigida por M. ${ }^{2}$ Teresa Echenique Elizondo y defendida en la Universitat de València en junio de 2013).

${ }^{2}$ Herramienta que destacó en su día Echenique Elizondo (2013) y que posteriormente ha empleado Espinosa Elorza (2014) para abordar el influjo del italiano en la pronunciación palatal lateral castellana de los infinitivos con pronombre clítico.
} 


\section{GÉNESIS Y DESARROLLO DE LA PALATAL LATERAL / $/ /$}

Los investigadores coinciden en datar la aparición de este fonema palatal en dos segmentos cronológicos: la primera $[\Lambda]$ que apareció en el latín hablado, procedente de los segmentos $\left[-1 \mathrm{lj}-,-\mathrm{k}^{\prime} \mathrm{l}-\mathrm{y}-\mathrm{g}^{\prime} \mathrm{l}-\right]^{3}$, y una segunda $[\Lambda]$ más tardía, originada a partir de las secuencias [pl-, kl-, fl-] y [-1.1- $]^{4}$. El camino evolutivo de este fonema ha sido recientemente descrito por André Zampaulo (2014: $170)$, para quien la primera $[\Lambda]$ :

[...] debió seguir un proceso evolutivo mediante el cual — durante el período del proto-español - se deslateralizó en un segmento palatal central (deslizado o fricativo) que fue ganando fricción y adelantando su punto de articulación hasta que dio lugar a la sibilante postalveolar /3/ en el castellano antiguo.

Creemos, al igual que Dámaso Alonso (1972 [1962]), que debieron existir procesos intermedios en el paso $[K]>[3]$, en casos como *[mu.'Ker] > [mu.'3er] (< MULIĒRE), a través de un segmento palatal africado. Según Alarcos Llorach (1991 [1965]: 261-262) y Lloyd (1993), el resultado de [-1j-] tuvo que diferenciarse de la palatal lateral originada tras la simplificación de la geminada [-1.1-]; por ello, se palatalizó en una consonante africada sonora $^{5}$ que nunca pudo llegar a ser una articulación de tipo yeísta, sino, más bien, una palatal deslateralizada africada sonora que, tras debilitarse, originó la prepalatal fricativa sonora $[\Lambda]$.

Por los datos expuestos no parece del todo convincente pensar que este elemento intermedio fuera del tipo *[mu.'jer] o*[mu.'jer] (Zampaulo, 2014), en contraste fonológico con la palatal central ${ }^{6}$ derivada de la yod tercera [-dj-, -gj-, -bj-], la semivocal latina [j-] y de [g + e, i], puesto que, si esta palatal lateral se deslateralizó en una articulación palatal central antes de articularse como [3], ¿por qué no se dio un yeísmo generalizado en la etapa medieval? Según Ariza

3 El resultado palatal de [-b'l-] es raro (Echenique Elizondo y Martínez Alcalde, 2013): TRĪBŬLU > ['tri.Ko]. Lo más esperable es el mantenimiento de este grupo consonántico latino, como es el caso de FABULARE $>$ [fa.'blar $]>$ [ha.' $\beta$ lar $]>$ [a.' $\beta$ lar $]$.

${ }^{4}$ No faltan testimonios en castellano de un resultado simplificado: COLLEGIU $>$ colegio, solución generalizada en gallego-portugués. ¿Existió en este caso una etapa intermedia de geminación castellana anterior al resultado simplificado?

5 Como ya apuntó Alarcos Llorach (1981), en castellano primitivo debieron coexistir una africada palatal sonora y una sorda. Por ello, parece convincente mantener la siguiente secuencia evolutiva para los segmentos [-lj-], [-k'l-] y [-g'l-]: $[\Lambda]>*\left[\mathrm{~d}_{3}\right]>[3]$.

${ }^{6} \mathrm{La}$ deslateralización de una palatal lateral $/ \Lambda /$ no puede interpretarse como desfonologización de una oposición $/ K /-/ \mathrm{j} /$ "desde el momento en que tal oposición nunca ha existido [...] pues [...] pertenecen a dos clases fonemáticas fundamentalmente diferentes" (Veiga, 2009 [2000]: 311). Se puede inferir de estos datos que la deslateralización de $/ \Lambda /$ en una palatal fricativa central en época protorromance habría conducido a una confusión más generalizada y, en consecuencia, habría que admitir un estadio de yeísmo en época temprana. 
Viguera (2012), la documentación más antigua de este fenómeno, que no debe confundirse con el yeísmo leonés temprano ${ }^{7}$, es de 1319 ; la rima de los textos poéticos, además, constata empleo diferenciador entre los fonemas palatal lateral y palatal central a lo largo de todo el período medieval (Pla Colomer, 2014a), por lo que la confusión o yeísmo no habría llegado a formar parte del sistema fonológico distintivo de la lengua castellana ${ }^{8}$. Sirvan, para este caso, las siguientes rimas de Juan del Enzina:

(1) Oy una virgen doncella $<*$ DOMNICILLLA

[...]

el claro sol de la estrella, $<$ STĚLLA

oy se pierde la querella $<$ QUERELLA

$[\ldots]$

oy se cubre nuestra mella, $<*_{\text {GEMELLA }}$

oy se amata la centella < SCǏNTǏLLA (Juan del Enzina, La Natividad, 109-116).

Llegaron estos tres Reyes, < REGES

$[\ldots]$

al pastor de tantas greyes $<$ GREGES

como quando van los bueyes < BŎvES (Juan del Enzina Los tres Reyes Magos, 171-174).

Lloyd (1993) apunta a un incipiente yeísmo en la obra del Libro de Alexandre, documentado en el ms. $P$ (llago por yago) y en el ms. $O$ (yeva por lle$v a$ ); no obstante, al tratarse de ejemplos gráficos, cabe pensar que dicha confusión se debiera a la mano del copista, y no a la del poeta original, como confirma el análisis de las rimas, en que la distinción entre los dos fonemas es absoluta.

7 "Parece claro que estas grafías [hace referencia a $<\mathrm{i}>\mathrm{o}<\mathrm{g}>$ ] indican una realización no lateral, y como es demasiado temprano para suponer un influjo castellano, hemos de pensar que reflejan una realización palatal central" (Ariza Viguera, 2009: 129). La diferenciación castellana es un rasgo que comparte con el aragonés y el riojano durante el siglo XII. Asimismo afirma Marcet (2008: 82): "Así pues, consideramos que no debe atribuirse necesariamente a un temprano influjo del castellano el empleo de las grafías $i, j$ en los documentos [...] compuestos en la primera mitad del siglo XIII, concretamente en 1234, 1239 y 1244, sino que perfectamente puede interpretarse como una práctica escrituraria marginal - fruto de la improvisación, el desconocimiento o la experimentación gráfica de los primeros años del romance escrito-, que barajaba opciones para hallar un representante adecuado del sonido consonántico [y]".

${ }^{8}$ Penny (2005 [2004]: 607) puntualiza que en el siglo XV encontraríamos diversos focos peninsulares que sirvieron de expansión del fenómeno del yeísmo "zonas de Aragón y del Oriente de Castilla, así como ocurrió en Toledo a finales del XV y, más generalizado, en Andalucía". La apertura de este proceso seguramente habría sido anterior: "[...] no es una repentina mutación fonética, sino más bien la prolongación geográfica y social de fenómenos que ya se daban [...] en siglos anteriores" (Alarcos Llorach, 1965: 48). Además, donde la confusión era un fenómeno esporádico, la reacción fue la tendencia a la eliminación de dicho fenómeno (Lloyd, 1993). 
A finales del siglo $\mathrm{XV}$, el yeísmo habría estado muy extendido en el habla popular, sin ser un fenómeno totalmente generalizado, como así lo demuestra su estado variable en Hispanoamérica. En concordancia con los datos que ofrece la poesía, la distribución de este fenómeno en la actualidad pone de manifiesto el mantenimiento de esta diferenciación según razones, entre otras, sociolingüísticas: "entre el campo [...] y la ciudad [...] en Murcia, en Albacete y en zonas de Canarias" (Ariza Viguera, 2012: 210).

\section{ARTICULACIÓN GEMINADA LATERAL EN LA HISTORIA DE LA LENGUA CASTE- LLANA}

Describir la naturaleza fonológica de un elemento en su sistema lingüístico actual es paso previo necesario al estudio de carácter diacrónico. Comparto con Veiga (2009 [1997]: 257) la noción de "sonido geminado", a la luz de la cual es preferible transcribir la geminada lateral como [-1.1-], en lugar de [-1:-], en tanto representa un elemento heterosilábico:

[...] lo único que cuenta desde el punto de vista funcional es que cualquiera de los dos momentos silábicos integrantes de un sonido geminado puede resultar conmutable en estricta igualdad de circunstancias, lo que prueba la funcionalidad independiente de ambos momentos y, en suma, la bifonematicidad de los geminados. Entre geminados y grupos heterosilábicos heterorgánicos hay, insistamos en ello, una diferencia de detalle fonético, pero no de estructura fonológica, pues esta es funcionalmente binaria en ambos casos.

Desde el punto de vista de la lingüística sincrónica, la lengua castellana presenta abundantes sonidos geminados, sobre todo en contextos donde actúa la fonética sintáctica, como en el sintagma el libro [el.'li.ßro], fenómeno que, como apuntó Pensado (1993: 396), existió también en épocas anteriores9: "La interpretación más sencilla para este tipo de casos es pensar que la secuencia $l+l$ se podía conservar en la pronunciación lenta y cuidada como efecto del mantenimiento de la conciencia morfológica".

En el caso del español hablado en Andalucía el encuentro entre [-r] final de un infinitivo y [1-] inicial de un pronombre personal ocasiona, entre otros resul-

\footnotetext{
${ }^{9}$ Es el caso de Nebrija en su Ortografía (cfr. Marcet, 2006: 669 n. 86): "escrivimos esso mismo en algunos lugares $l$ senzilla e pronunciamos la doblada, como quando a los nombres femininos que comiençan en $a$, porque no se encuentre una $a$ con otra y haga fealdad en la pronunciación, dexamos el artículo del femenino y tomamos el artículo del masculino, como por dezir: la alma, la aguja, la açada, dezimos con doblada l: ellalma, ellaguja, ellaçada, pero escrevimos e pronunciamos, como diziendo la espada, el espada, el lespada"; de igual modo se constata en la obra del gramático Correas (cfr. Pensado, 1993: 201): "[...] la $l$ final siguiéndose otra detiene un poco para apartarlas".
} 
$\operatorname{tados}^{10}$, una articulación prolongada binaria lateral. De igual modo, la solución palatalizada convive con otras variantes y "nunca [aparece] en solitario y ni siquiera como solución predominante, en los puntos más meridionales de la comarca cordobesa de la Subbética y en el área más septentrional de la provincia de Málaga" (Narbona Jiménez, Cano Aguilar y Morillo-Velarde, 2011: 213214). Los datos apuntan a una situación lingüística de convivencia heterogénea de variantes, como debió ocurrir en épocas anteriores.

En este sentido, resultan iluminadores los datos que ofrece la lengua morisca, desconocedora de la consonante palatal lateral, ya que a sus hablantes se les hacía pronunciar [-1j-] para facilitar su articulación (Narbona Jiménez, Cano Aguilar y Morillo-Velarde, 2011: 98), hecho que demuestra la vinculación del fonema palatal $/ \Lambda /$ con el alveolar $/ 1 /$ : “[...] el único fonema de todo el sistema fonológico español con el que $/ K /$ establece una relación de oposición directa es /1/, fonema igualmente integrado en la clase de los líquidos y, dentro de ella, en la subclase de los líquidos continuos" (Veiga, 2009 [2000]: 311).

Parece indudable que la geminación no resulta del todo ajena a las posibilidades fónicas de la lengua castellana, como así lo constata el estudio de Pensado (1993), quien postuló la existencia de una articulación geminada lateral [-1.1-] que se prolongó a lo largo de la Edad Media, en contraste con una pronunciación palatal [- $\Lambda$-]. Desde esta convicción, a continuación tiene lugar el análisis de una selección de poemas medievales, cuyas rimas ponen de manifiesto que las grafías $<\mathrm{ll}>\mathrm{y}<\mathrm{l}>$ encubrían otra solución distinta a las laterales palatal y alveolar, respectivamente. Para ello, hemos dividido el corpus ${ }^{11}$ en dos grandes grupos que creemos necesarios para aclarar los contextos fónicos relacionados con la emergencia de un sonido geminado lateral:

(i) mantenimiento de una antigua geminada, procedente de -LL- latina, que seguramente convivió con la solución predominante palatal, en tanto "todavía después de la invasión árabe $[1.1, \mathrm{n} . \mathrm{n}] \mathrm{y}[\Lambda, \mathrm{n}]<-\mathrm{LL}-,-\mathrm{NN}-$ podían coexistir" (Pensado, 1993: 196);

(ii) geminación no etimológica, originada por contactos morfosintácticos, ya que "las lenguas que no tienen geminadas en sus inventarios fonológicos pueden tolerarlas de hecho en ciertas circunstancias" (Pensado, 1993: 193).

10 "[...] la asimilación completa en una $l$ - simple, que da como resultado formas como decilo, hacelo, etc.; y la transformación de ambas consonantes en $y$, dando deciyo, haceyo, etc." (Narbona Jiménez, Cano Aguilar y Morillo-Velarde, 2011: 213).

${ }^{11}$ Los ejemplos empleados proceden del despojo completo de ediciones fidedignas, recogidas en las fuentes primarias de la bibliografía (5.1.), y en unos pocos ejemplos de la base de datos electrónica $C O R D E$, en cuyo caso, se hará mención explícita. 


\section{1. ¿Reductos de una antigua geminada latina?}

La articulación palatal lateral podría haber coexistido con la geminada, como mínimo, desde la invasión árabe, como se observa en los versos de la lírica arábiga, en que la disimilación ([-1.1- $\left.]>[-1 . d-]^{12}\right)$, documentada también en aragonés, y la simplificación ([-1.1-] > [-1-]) se revelan como testimonios de una pronunciación geminada (BULLA $>$ bulda, REBELLE $>$ rebelde, PILLULA $>$ píldo$r a$, APPELLARE $>$ apeldarse), en alternancia con la simplificación (bula, rebele). Por ello, apoyamos la primera conclusión: existió una pronunciación geminada en castellano durante la Edad Media, por lo que el mantenimiento de la grafía $<$ ll $>$ no encubría exclusivamente una pronunciación palatal.

El estudio pormenorizado de la fonética y fonología históricas, en relación con los acontecimientos históricos estrechamente vinculados con la corte, proporciona una serie de resultados que son en sí mismos la clave para delimitar las diferentes etapas de una periodización (Echenique Elizondo y Pla Colomer, 2013). Por esta razón, al igual que en trabajos anteriores (Pla Colomer, 2014a), hemos recurrido a los reinados como segmentos cronológicos de acuerdo con la propuesta hecha en su día por Gómez Redondo (1998), reforzada ahora para cuestiones métricas y su relación con la historia de la lengua por Beltran (2009a) y Gómez Redondo (2016), metodología que forma parte de una concepción integral de la filología.

\subsubsection{Fernando I el Grande (1035-1065)-Enrique I (1214-1217)}

Los primeros testimonios poéticos en lengua castellana documentan empleo abundante de la grafía $<\mathrm{ll}>$, e incluso $<\mathrm{li}>$, para representar el sonido palatal lateral sonoro. Es el caso de $<$ fallir $>$, <lieuo $>$ y $<$ cauallos $>$ ([fa.' Kir], ['Ke.ßo] / ['lje.ßo] ${ }^{13}$ y [ka.'ßa.Kos]) de la Disputa del alma y el cuerpo; sin embargo, en el Auto de los Reyes Magos la grafía simple $<\mathrm{l}>$ podría representar tres tipos de articulación: la alveolar simple [-1-], la palatal lateral [- $\Lambda-]$ y la geminada lateral [-1.1-]:

(2) Dios criador, qual marauila $<$ MIRABILIA no se qual es achesta strela $<$ STĔLLA (Auto de los Reyes Magos, 1-2).

\footnotetext{
12 Recuérdese, en contraste con el castellano, que este segmento fónico desembocó tempranamente en leonés en una articulación palatal: “[...] la palatalización tanto de [1-] como de [ld] habría sido general en buena parte de los dominios del leonés durante el siglo XIII y centurias anteriores, pero los escribas habrían optado por no reflejarla en la escritura no por considerar-la un rasgo rústico, sino por resultar innecesario" (Marcet, 2007: 12).
} 
La rima entre $<$ strela $>\mathrm{y}<$ marauila $>$ parece que apunta a una articulación palatal lateral, en tanto la aparición de la articulación vibrante en el segmento [st-] latino es solución genuina iberorromance de formación tardía en el momento en que ya se habría dado la palatalización de la geminada latina. El resultado simplificado es propio del portugués estrela y del catalán occidental estrela (o estrella); al tiempo que la variante que persiste en catalán oriental es estel, correspondiente a la solución galorromance étoile. En caso de admitir la articulación simplificada [s'tre.la] o geminada lateral [s'trel.la], más acorde con el resto de soluciones iberorromances, la rima con [ma.ra.' $\beta$ i.Ka] adquiriría pleno sentido si se consideraran ambas articulaciones como elementos fónicos estrechamente relacionados.

\subsubsection{Fernando III el Santo (1217-1252)-Fernando IV el Emplazado (1295-1312)}

La "geminación" se ajustaría con adecuación al estilo lento y cuidado de la cuaderna vía del mester de clerezía; sin embargo, su escasa documentación en posición de rima parece indicar que no se trataba de un elemento compositivo del paradigma fonológico del castellano, sino de una variante articulatoria minoritaria frente a las abundantes rimas consonánticas con palatal lateral. La siguiente rima apunta a la hipótesis de la existencia de una articulación geminada etimológica en el siglo XIII:

(3) Glaucas, en est' comedio, buscó abze mala: < MALA fallós' con Dïomedes en medio la batalla. < BATTUALǏA ¡Cuedós‘ que lo podrié derrocar sines falla ${ }^{14}<$ FALLA e dioli un grant colpe en medio de la tavla! < TABŬLA (Libro de Alexandre, 573).

La rima atestiguada en los manuscritos $O$ y $P$ entre mala, tavla $(<$ tabla $>$ en el manuscrito $P$ ) y batalla, cuyo étimo próximo es la voz bataille, procedente

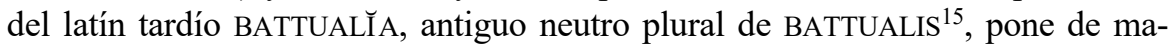

${ }^{13}$ Hay que tener en cuenta que la interpretación de esta grafía no es unívoca.

14 Según Corominas y Pascual (2006-2007 [1980-1991]: s. v. falla) "las formas antiguas falir, falimiento, etc., registradas por la Acad., serán grafías imperfectas de la pronunciación fallir". ¿Por qué deberían ser tratadas como grafías imperfectas cuando del latín FALLAX $>$ falaz? El resultado simplificado convivió con otras variantes, como se infiere de la rima del Libro de Alexandre. De igual modo, hoy en día conservamos el doblete léxico falta y fallido/a, procedentes de FALLITA, al tiempo que en toponimia se documentan dobletes como Vallelato, Vallelado, Valongo y Valouta, del latín VALLE (Montenegro, 1960: 514).

15 Corominas y Pascual (2006-2007 [1980-1991]: s. v. batalla). Covarrubias (1611: s. v. BATALLA) arguye sobre el étimo de esta voz: "Los gladiatores, o soldados, antes que saliessen a matarse, o a pelear con las espadas blancas, como lo dize Adamantino martir por estas palabras: Batualia quae vulgo Batalia dicuntur, exercitationes gladiatorum, vel militum significant". 
nifiesto la articulación geminada de $<1 \mathrm{l}>$; en tanto batahola 'algazara', forma antigua de batalla, y el catalán tabahola, cuyas consonantes líquidas representan un sonido lateral no palatal, comparten el mismo étimo. La existencia de una geminada [-1.1-] permitió al poeta del Libro de Alexandre elaborar una rima consonante (batalla, falla, mala y tavla), a pesar de que, desde el sistema fonético-fonológico del castellano actual, sea claramente percibida como asonante.

La siguiente rima es testimonio fidedigno de las posibilidades fónicas que encubría $<$ ll $>$ :

(4) matare yo, e mas de mill < MILLE

por aquel malo e vil < VILE (Historia troyana, poesía I, 112-113).

La pérdida vocálica en MILLE impidió la palatalización de la consonante intervocálica, que terminó simplificándose ([-1.1-] $>$ [-1]). La posición de $<$ mill $>$ en final de verso, que en esta época imposibilitaba cualquier fenómeno de fonética sintáctica (debido a la inexistencia de los encabalgamientos), en rima con la voz vil (['ßi.le] > ['bil]), justifica que la grafía doble de este numeral, cuyo uso seguirá vigente en el reinado de los Reyes Católicos ${ }^{16}$, era arcaísmo gráfico heredado de la tradición literaria de mayor prestigio.

\subsubsection{La corte letrada de Alfonso Onceno (1312-1350)}

En contraste con la centuria precedente, los poemas del segundo ciclo del mester documentan mayor número de rimas que apuntan a la pervivencia de la articulación geminada lateral. Es el caso de la rima del Libro de miseria de omne (Pla, 2015a) entre <mortales, valles, piñascales y males>:

(5) Por amor de ganar algo, los omnes que son mortales < MORTALES andan, corren e trastornan por oteros e por valles; < VALLES fazen vías e caminos por sierras e piñascales; $<$ der. PĪNNA desende pasan la mar, en que sufren muchos males. < MALES (Libro de miseria de omne, 88).

La convivencia de variantes arcaicas junto a las innovaciones fonéticas permitió a Juan Ruiz caracterizar la lengua de los personajes que pueblan el mundo plural del Libro de Buen Amor (Pla Colomer, 2015b) desde el punto de vista diastrático (episodio de las serranas) y diatópico (la lengua de don Pitas Payas). La lengua del Arcipreste de Hita es reflejo de una época de cambio, en

${ }_{16}$ Así lo recoge la tradición lexicográfica bilingüe: Nebrija (1516), Palet (1604), Oudin (1607), e incluso en la obra de Mez de Braidenbach (1670) "Mil, ò mill", según datos extraídos de la base electrónica NTLLE (s. v. MILL). 
que los arcaísmos más marcados se funden con innovaciones lingüísticas en un texto poético que revolucionó el mester a sílavas contadas.

(6) El día del domingo, por cobdicia mortal, < MORTALE combrás garvanços cochos con azeite e non ál; < ALTERU irás a la iglesia, no estarás en la cal', < CALLE que non veas el mundo nin cobdicies el mal. < MALE (Libro de Buen Amor, 1163).

La articulación líquida en posición final absoluta de mortal y mal es sonido permitido por la lengua castellana tras pérdida de vocal. Llama la atención la voz cal', lectio documentada en los manuscritos $S$ y $G$, procedente del latín CALLE 'senda, camino', que tras sufrir el proceso de apócope extrema debió originar en la lengua antigua una palatal lateral, en convivencia con otras soluciones, tolerada según la naturaleza silábica del castellano antiguo (Catalán, 1989 [1971]), como queda patente en el resultado con vocal restituida en época posterior; sin embargo, la rima con mortal, al y mal es indicio de que, en este caso, su articulación no era palatal ${ }^{17}$. Asimismo, tampoco sería imposible pensar en la pervivencia de un sonido geminado lateral previo a la caída de la vocal final, o incluso alveolar simple compartido con la zona leonesa, como atestigua la siguiente documentación extraída de CORDE:

(7) de la primera parte la caleya que vien de los Cardielles para las casas de Sant Noual, de la segunda la cale que ua para la plaça de Santa María de Regla (Anónimo, Carta de trueque [Documentos de la catedral de León], 1303).

De igual modo ocurre en la rima de la siguiente estrofa:

(8) si dava tino a otro fuego o la candela, < CANDĒLA amatávase luego; venién todos a ella, < ILLLA encendién allí todos como en grand centella. < SCǏNTǏLLA Assí vengó Virgilio su desonra e querella. < QUERĒLLA (Libro de Buen Amor, 264).

\footnotetext{
${ }^{17}$ Corominas y Pascual (2006-2007 [1980-1991]: s. v. calle) afirman que "en la E. Media es corriente la variante cal"; más adelante añaden: "En construcción proclítica (cal de..., cal + adjetivo) llega hasta el s. XVII"; así lo recoge Covarrubias (1611: s. v. calle): "[...] y en muchas partes le cortan la postrera silaba, y dizen Cal, como Cal de Francos". El proceso de creación de esta variante castellana no parece estar en relación con la simplificación de la geminada lateral del rumano cale, portugués cale o lombardo cala, soluciones que documentan Corominas y Pascual. A partir de Nebrija (1492), la tradición lexicográfica lematiza esta voz con valor palatal lateral, según orden alfabético, después de callar o callada, tras la relación de voces que presentan líquida lateral (caluniar).
} 
La consonante líquida lateral de la voz candela está en posición de rima con ella, centella y querella, estrofa conservada exclusivamente en el manuscrito $S$, por lo que las desinencias de estas voces se pronunciaron con geminada lateral en un momento en que la confusión articulatoria era una realidad, es decir, la proximidad fónica entre la palatal lateral y la geminada hizo posible la rima consonántica de esta estrofa.

La variabilidad gráfica entre $<1>$ y $<11>$ de los Proverbios morales de Sem Tob (Pla Colomer, 2018) trasluce pervivencia de la articulación geminada lateral latina que, sin embargo, para Alarcos Llorach (1951: 271) supone "combinaciones de una consonante alveolar con un elemento semiconsonántico palatal; mejor dicho, en su sistema semítico, combinaciones de un nun o un lam sucunados y un $y \bar{a}$ vocalizado". La rima homoioteleuton ${ }^{18}$ imposibilita conocer con total exactitud la articulación de la consonante intervocálica; no obstante, la elección de las voces en rima, en consonancia con las distribuciones léxicas de los textos poéticos de la escuela del mester, así como su representación gráfica en la totalidad de los manuscritos conservados (<-11->), apoya la existencia de una articulación cercana a la geminación en la lengua castellana tardomedieval. Es el caso de la rima interna entre <querellas $>$ y $<$ rebellas $>$ ([ke.'rel.las] y [re.'Bel.las]):

(9) Fi d'omre, ¿que't querellas cuando lo que't plaze < QUERELLAS non se cumple, e rrebellas en Dios porque non faze $<$ REBELLAS (Proverbios morales, 298).

\subsubsection{La corte Trastámara (1351-1454)}

Las composiciones líricas recogidas en cancioneros, junto al Rimado de Palacio de López de Ayala, representante último de la escuela del mester (Pla Colomer, 2014b) y gran intelectual de su época, traslucen en sus rimas la pervivencia de una pronunciación geminada lateral:

(10) Si fabla o dize, maguer que bien fable, < FABULET

su fabla de todos es muy aborrida, e luego le dizen los ricos que calle, $<$ CALLE que assí su razón no 1‘ será oída; (Ruy Páez de Ribera 289, 6).

La forma plena $<$ calle $>$ de la estrofa de Ruy Páez de Ribera en rima con fable, voz que no contiene una articulación palatal, es ejemplo que pone de manifiesto una secuencia no palatal para <calle> (['kal.le] / ['ka.le]).

${ }^{18}$ Rima de los últimos elementos silábicos átonos. Sem Tob compuso versos alejandrinos heptasílabos isosilábicos $(7+7)$ con rimas internas, idea compartida por las ediciones de González Llubera (1947), Díaz-Mas y Mota (1998) y especialistas como Alarcos Llorach, Deyermond, Domínguez Caparrós, Mota o Ivanovici, entre otros muchos. 
Los siguientes ejemplos arrojan luz a las posibilidades fónicas que encubrían las grafías $<-11->$ y $<-1->$ :

(11) E pois que non ha manzela $<$ MACELLA

de miña coitada morte,

si osasse, en toda corte

diría miña querela; < QUERELLA

mais d'ela he pavor que ha poder

tal que non oso dizer

si es doña nin donzella. <*DOMNIČLLLA (Álvarez de Villasandino 10, 3).

$[\ldots]$

chaman todos linda estrela; $<$ STĚLLA

si es dona o donzela $<*$ DOMNIČ́LLA (Álvarez de Villasandino 24, 6).

Quien te apela maristela, < MARE STĚLLA

flor del ángel saludada,

sin cabtela non reçela $<$ REZELAT

la tenebrosa morada; (Álvarez de Villasandino 1,5).

Las dos primeras rimas de Álvarez de Villasandino revelan pronunciación líquida lateral de estrela, donzela y manzela propia del dominio lingüístico gallego, incluso para la variante gráfica $<$ donzella $>$, cuya grafía doble $<1 l>$, atestiguada en el manuscrito Esp.37 de París, no encubría una articulación palatal ${ }^{19}$; por el contrario, la grafía $<\mathrm{l}>$ de $<$ maristela $>$ pudo ser un préstamo, ya que, en este caso en concreto, la estrofa en que se inserta presenta rasgos lingüísticos castellanos, en tanto: "La poesía cancioneril castellana es consecuencia del influjo cultural causado por la tradición gallego-portuguesa durante los siglos XIII-XIV" (Gómez Redondo, 2016: 1168).

Comparto la opinión de Corral Checa (1992: 230), basada en la idea de que en la obra de Mena se mantiene la representación gráfica de la consonante geminada $<1 \mathrm{l}>$ con el mismo valor fónico, como lo corroboran las siguientes rimas:

(12) Acloceramina, Sçilla, < SCILLA las ravias desenfrenadas que de fuegos inflamadas demostravan grand quadrilla. < QUADRĔLLA (Juan de Mena, la Coronaçión XXI, 202-205).

${ }^{19}$ Como recoge Lapesa (2010) en su esbozo de edición del Rimado de Palacio, en el manuscrito aparece la variante gráfica <apelar>, grafía propia de la líquida lateral, por lo que se debería mantener o dicha grafía o, en el caso de que se utilizara la grafía doble, no apuntaría a una pronunciación palatal; así lo documenta, casi un siglo después, la rima de Diego de San Pedro entre apela, desvela y duela: "De lo cual pobreza apela, / que aunqu'el mundo se consuma, / ni vela ni se desvela, / ni tiene de qué se duela / ni tiene de qué presuma" (Diego de San Pedro, Desprecio de la Fortuna, 14). 
El nombre propio Sçilla debió haber mantenido la articulación geminada etimológica ['tsil.la] que, tras su simplificación, derivó en la consonante líquida conservada hasta hoy día. De esta manera, parece difícil aceptar una articulación palatal para esta voz, por lo que su rima perfectamente consonante con quadrilla, articulada seguramente con palatal lateral, revela que ambos sonidos estuvieron vinculados.

(13) Vet si queredes la gente que queda darme liçencia que la señale, < SIGNALEM mas al presente fablar non me cale: < CALET verdat lo permite, temor lo devieda. (Juan de Mena, Laberinto de Fortu$n a$ XCII, 733-736).

Creemos, al igual que Kerkhof (1995), que non me cale tiene el significado de "no me importa, no me conviene'20. La forma verbal no estaría relacionada con el étimo latino *CALLARE 'callar', sino con CALARE 'soltar, hacer bajar' (Corominas y Pascual, 2006-2007 [1980-1991]: s. v. calar), por lo que la rima entre esta forma verbal y señale [se.'na.le] confirma la articulación alveolar de $<$ cale $>21$, que mantuvo una oposición fonológica con la palatal ['ka.Ke] 'callar'22. Esta descripción etimológica se ve reforzada por el significado de estos versos 'no me conviene hablar del que vive', sentido que recoge Hernán Núñez de Toledo en las Glosas sobre las Trezientas del famoso poeta Juan de Mena (1499):

Porque si escrives los vicios de los que son bivos, como Tigilino y otros, mandarte han quemar, como dize Juvenal. Si dizes de los muertos, como Mucio, que ha mucho que está enterrado, no recibirás detrimento [...]. Por ende, Juan de Mena como prudente guardóse de escrevir de los bivos (Weiss y Cortijo, 2015: 438).

El mismo rasgo parece documentarse en algunas estrofas de Î́nigo López de Mendoza:

(14) Yo fize los pueblos de Tebas e Attenas, e las sus murallas levanté del suelo; $<$ SŎLU de mí resçibieron folganças e penas, e prósperas fize las lides de Bello. < BELLU

${ }^{20}$ Es el mismo significado que encontramos en 1438 en el Corbacho de Alfonso Martínez de Toledo, según datos del CORDE: "antes, sy alguno mal dixere o detractare al contynente, a él non le cale "rresponder, que todos a una voz rresponderán por él".

${ }^{21}$ MH1 ofrece la lectio <calle> (Kerkhof, 1995: 299), dato que constata el uso de la grafía $<1 \mathrm{l}$ para soluciones articulatorias no palatales.

${ }^{22}$ Así lo confirma la siguiente rima: "e quando de noche la gente más calla, / pónelo ésta en medio de un cerco / e desde allí dentro conjura en el uerco, / e todas las sombras ultrices sin falla" (Juan de Mena, Laberinto de Fortuna CCXLV, 1957-1960). 
$\mathrm{Al}$ ave de Jove conplí de gran buelo, < VŏLU

e puse discordia entre los hermanos;

todas las cosas vienen a mis manos,

si prósperas suben, assí las assuelo. < ASSŎLO (Marqués de Santillana,

Comedieta de Ponça CXI, 882-888).

\author{
Antes el rodante cielo $<$ CAELU \\ tornará maso e quieto, \\ y será piadosa Alecto \\ e pavoroso Metello (Marqués de Santillana, Dezires 7, I, 1-4).
}

Las formas gráficas $<$ Bello $>$ y $<$ Metello $>$, que presentan una grafía doble $<-11->$, se habrían pronunciado, bien con la forma culta etimológica ['bel.lo] y [me.'tel.lo], bien con la solución simple ['be.lo] y [me.'te.lo], a partir de las rimas con las voces suelo, buelo, assuelo y cielo. Estos datos ponen de manifiesto la cercanía articulatoria de la geminada lateral [1.1] con la simple [1].

Sirvan los siguientes versos de Juan de Mena y el Marqués de Santillana para demostrar que muchas de las formas con grafía doble $<-11->$ en posición interna de verso encubrían una articulación simple o geminada:

(15) o qual Escilla de Niso su padre, < SCILLA (Juan de Mena 22-VII, 54)

Tus casos fallaçes $^{23}$, Fortuna, cantamos, < FAllaces (Juan de Mena, Laberinto de Fortuna II, 9).

de donde depende muy grande exçelençia ${ }^{24}<$ EXCELLENTǏA (Juan de Mena, Laberinto de Fortuna XXIII, 180).

${ }^{23}$ Contrasta el resultado no palatal de esta variante con la articulación palatal de $<$ falla $>$, asegurada por la rima con $<$ calla $>$ de la siguiente estrofa: "mas una si ovo, es otra sin falla, < FALLA / nueva Penélope aquesta por suerte. / ¡Pues piensa qué fama le debe la muerte / quando su gloria la vida no calla! < CALLAT" (Juan de Mena, Laberinto de Fortuna LXXVIII, 621-624).

${ }^{24}$ La edición anotada de Hernán Núñez (1499) ofrece la lectio <ecelencia>, al tiempo que el Brocense (1582) prefirió la variante <excellencia>. Kerkhof (1995), sin embargo, mantiene la grafía simple <eçelençia $>$. Las distintas posibilidades gráficas son reflejo de variación ortográfica que no afecta al plano fónico, por lo que tanto $<11>$ como $<1>$ encubrieron un sonido líquido lateral no palatal que, en el caso de la poesía culta cortesana, podría haberse pronunciado con cierto alargamiento con la finalidad de imitar la articulación geminada latina. Es el caso de la pronunciación [a.'po.lo] / [a.'pol.lo] (<Apollo $>$ ), [fla.'ze.lo] / [fla.'zel.lo] (<flagello $>$, lectio que mantiene Kerkhof, 1995) o [kom.'pe.les] / [kom.'pel.les] (<compelles $>$ ), de las variantes gráficas $<11>$ documentadas en la edición comentada del Brocense (criterio más cercano al original de Mena por la clara intención cultista y latinizante del poeta), en tanto las glosas de Hernán Núñez revelan preferencia por la grafía simple para todos estos casos, pues como afirman Weiss y Cortijo (2015: 175): "la preferencia [...] por formas ortográficas menos latinizantes cuadra bien con la decisión del autor [...] de eliminar las abundantes citas y de ofrecer a su público el comentario con un cariz más vernáculo": "en mí tu subsidio, immortal Apolo; / aspira en mi boca, por que pueda solo < SOLU" (Juan de Mena, Laberinto de Fortuna VI, 42-43); "feríalos ésta con duro flagello, < FLAGELLU / tanto que fizo fazerles tal buelo < VŎLU" (Juan de Mena, Laberinto de Fortuna XIII, 
illustre Reyna famosa. < ILLUSTRE (Marqués de Santillana, Canciones $7,17)$.

oí triste cantillena, < CANTILENA (Marqués de Santillana, Querella de amor I, 7).

Si mi baxo estillo ${ }^{25}$ aun non es tan plano, < STILU (Marqués de Santillana, Defunsión de don Enrique de Villena X, 77).

Las composiciones poéticas de la corte aragonesa de Alfonso el Magnánimo y Juan I de Navarra y II de Aragón también documentan la cercanía articulatoria que encubrían las grafías $<\mathrm{l}>\mathrm{y}<\mathrm{ll}>$. Es el caso del dezir de Juan de Tapia, compuesto antes de 1448 (Beltran, 2009a: 485), sobre la alabanza de un conjunto de damas de Calabria:

(16) Adoina et Penantela son más claras que el luzero, el alva pone primero la D'Aflito por aquella; < ACCU + كLLLA la desdeñosa pucela, < PULLICELLA la villana muy devota con la moça de la mota que es más clara que un estrella. < STĔLLA (Juan de Tapia 122, 6).

La rima de esta estrofa del tipo abbaacca exige que Penantela, aquella, pucela y estrella constituyan rimantes consonantes a partir del último acento tónico. Según Corominas y Pascual (2006-2007 [1980-1991]: s. v. poncella) poncella 'virgen, doncella' es voz tomada del catalán poncella, de origen incierto, que "aparece rimando en -ella en Berceo ${ }^{26}[\ldots]$, ponzela (o poncella en otro ms.) en Mil.". La forma que presenta este poema es claro orientalismo, relacionado con el catalán pucella y las variantes occitanas piuzela, piucela o pulcela. La articulación subyacente de la grafía $<\mathrm{ll}>$ de $<$ aquella $>$ y $<$ estrella $>$ debió ser lo suficientemente

102-103); “ ¡O miedo mundano, que tú nos compeles < COMPELLES / grandes plazeres fingir por pesares, / que muchos Enteles fagamos ya Dares, / e muchos de Dares fagamos Enteles!" (Juan de Mena, Laberinto de Fortuna XCIII, 737-740).

${ }^{25}$ La rima entre estilo y tranquilo del Laberinto de Fortuna constata articulación líquida para la variante culta $<1 l>$ de $<$ tranquillo $>$, ofrecida por la edición del Brocense. Nótese que los testimonios BM2 y MM1 mantienen la grafía doble para <stillo> (Kerkhof, 1995: 316), pese a que su étimo carecía de articulación geminada: "presto nos vengan a puerto tranquillo, $<$ TRANQUĬLLU / por que Castilla mantenga su estilo < STILU (BM2 y MM1: <stillo>)" (Juan de Mena, Laberinto de Fortuna CXLVII, 1174-1175).

${ }^{26}$ A la luz de otras rimas aquí analizadas, las grafías $<11>$ de los siguientes rimantes encubrían distintas soluciones fónicas, por lo que no puede asegurarse una articulación palatal lateral para estas voces: "Amava al so Fijo e amava a Ella, < ILLLA / tenié por sol al Fijo, la Madre por estrella; $<$ STĔLLA / querié bien al Fijuelo e bien a la ponzella, $<$ PULLICELLA / porque los servié poco sedié con grand querella. < QUERELLA" (Gonzalo de Berceo, Milagros de Nuestra Señora, IV, 117). 
próxima al de una articulación no palatal como para componer esta rima que creemos a todas luces consonante, ya que no encontraría lugar una única estrofa asonante a lo largo de un poema rimado con absoluto rigor ${ }^{27}$.

\subsubsection{Enrique IV (1454-1474)-los Reyes Católicos (1474-1504)}

Los poemas de cancionero correspondientes a la corte de Enrique IV (Juan Álvarez Gato, Gómez Manrique, Nicolás Guevara o Jorge Manrique), así como los de la corte de los Reyes Católicos (Fray Íñigo de Mendoza, Pedro de Cartagena, Garci Sánchez de Badajoz, Diego de San Pedro o Juan del Enzina), no revelan en sus rimas pervivencia de una articulación geminada etimológica, en tanto hacen coincidir en posición de rima voces con palatal lateral sin confusión con otros segmentos líquidos laterales.

El respeto por mantener la fonación latina clásica, fruto del aprendizaje de estos poetas, resultó en la composición de estrofas híbridas en cuyas rimas coincidieron segmentos de distintos diasistemas lingüísticos, como se observa en la siguiente estrofa de Garci Sánchez de Badajoz en que la rima entre $<$ sale $>$ y $<$ valle $>$ revela la antigua pronunciación geminada latina:

(17) O clara lumbre que sale $<$ SALIT

de la santa trinidad

que nos alumbra y nos guía

yn hac lacrimarum valle

o Clemens virgo Maria, (Garci Sánchez de Badajoz 81, 48-52).

\subsection{Articulación geminada no etimológica}

La asimilación de la vibrante final de infinitivo y la líquida alveolar del pronombre clítico resultó en una variante geminada líquida lateral que habría contendido con la forma originaria que mantenía inalteradas las dos consonantes líquidas ${ }^{28}$, soluciones que parecen haber compartido un período de existen-

\footnotetext{
${ }^{27}$ Teoría que parece confirmarse a la luz de las rimas de los poetas provenzales: "[...] los trovadores del Lemosín y del norte del dominio provenzal riman las voces derivadas de -ela -ala con las derivadas de -ella -alla, y son los trovadores del sur los que distinguen ambos fonemas, como Giraut Riquier, de Narbona" (Menéndez Pidal, 1960: LXXXVIII).

${ }^{28}$ Ariza Viguera (2009: 55) asimismo apunta a esta solución: "También es muy interesante la ¿asimilación? de la / $\mathrm{r}$ / del infinitivo en sabelo $-\mathrm{v}$. 52- y adoralo $-\mathrm{v}$. 106- $\mathrm{y}$ en donde la falta de la grafía de la doble $<1>$ nos puede hacer pensar que la pronunciación era bien 1.1, bien $/ K /$ " Según Espinosa Elorza (2014: 15), para el dominio leonés: "no haría falta pensar en un proceso de asimilación $>$ geminación $>$ degeminación, dado que en ellos se produce con frecuencia la pérdida de $[-r]$ de los infinitivos".
} 
cia común en la Edad Media. La posible influencia que ejercieron el leonés y el gallego-portugués, en una primera etapa, y el italiano, en plena época renacentista, fueron determinantes en el incremento de la pronunciación con consonante palatal (Espinosa Elorza, 2014), que ha subsistido en el Mediodía peninsular como vulgarismo (Lapesa, 1981).

El análisis de las siguientes rimas tiene la finalidad de demostrar la coexistencia de estas variantes desde el siglo XII hasta el reinado de los Reyes Católicos; queda, por tanto, para futuras investigaciones, centrar el punto de atención en la poesía de la corte de los Austria para arrojar luz a un fenómeno que encuentra sus orígenes y desarrollo en época medieval.

\subsubsection{Fernando I el Grande (1035-1065)-Enrique I (1214-1217)}

Las asimilaciones entre verbo y enclíticos o preposición y artículo parecen indicio de la alta frecuencia de articulaciones geminadas en posición de sandhi externo, es decir, como marca fonética del límite de palabra ([-1\#1-]). No parece imposible pensar en el uso de la grafía <-1l- > y <-rl-> en representación tanto del sonido geminado [-1.1-] como [-r.l-], soluciones que, en coexistencia con una variante palatalizada, continuaron vigentes en la lengua oral más generalizada con distribución geográfica heterogénea.

De esta manera, desde el reinado de Fernando I hasta el de Enrique I se documenta la coexistencia de variantes en posición interna de verso: <aoralo>, que encubría una articulación bien geminada [ao.'ral.lo], bien simplificada [ao.'ra.lo], y <saberlo>, que mantenía inalteradas las dos consonantes líquidas [sa.'ßer.lo]:

(18) Ala ire o que fure, aoralo e < ADORARE + ILLU (Auto de los Reyes Magos, 17).

Dezidme la uertad, de uos saberlo quiro < SAPERE + ILLLU (Auto de los Reyes Magos, 53).

\subsubsection{Fernando III el Santo (1217-1252)-Fernando IV el Emplazado (1295-1312)}

La asimilación de las dos consonantes líquidas, y el consecuente alargamiento compensatorio, en convivencia con la pronunciación palatal, justifica las siguientes rimas consonantes del siglo XIII, todas ellas compuestas por la forma de infinitivo y pronombre clítico, por un lado, y elementos nominales procedentes de -LL- latina, por otro:

(19) Ante que lo sopiessen, el infant‘ fue con ellos: < ǏLLOS 
alçar non se podieron e ouo a vençerlos ${ }^{29} ;<$ VINCERE + كLLLOS

¡fizo tal escarmiento e tal danno en ellos, $<$ ÍLLOS

que a los nietos öy se alçan los cabellos $^{30}$ ! < CAPILLOS (Libro de Alexandre, 166).

Fue ferir a Achiles a poder de cavallo: < CABALLU

¡asmó, si‘s le feziés‘, de voluntad matarlo! < MACTARE + ǏLLU

Firme estido Achiles; non dubdó esperarlo ${ }^{31}:<$ SPERARE + ILLLU

¡non dio por ello más que si‘l picás‘ un gallo! < GALLUS (Libro de Alexandre, 682).

${ }^{29}$ Ms. $O$ : $<$ uençerllos $>$; ms. $P:<$ vençerlos $>$. La grafía doble $<11>$ de $O$ es claro rasgo leonés.

${ }^{30}$ En los Milagros de Nuestra Señora, Berceo rima $<$ cabello $>$ con $<$ flabello $>$, tomado de FLABELLU 'abanico' (Corominas y Pascual, 2006-2007 [1980-1991]: s. v. flato), que ha pervivido con la variante simplificada flabelo. Si en castellano medieval existió una forma palatalizada, la rima constata dicha pronunciación para todas las voces en posición de rima; sin embargo, no parece improbable que se pronunciara con una consonante líquida lateral representada con una grafía latinizante $<11>$, ya que, a la luz de los datos expuestos, estos sonidos estaban estrechamente vinculados entre sí (como así ocurre con la representación gráfica de $<$ cancellario $>$, procedente del latín tardío CANCELLARIU del verso 107a del mismo texto: "Mándote que lo digas: que el mi cancellario / non merecié seer echado del sagrario"): "Nin ardió la imagen nin ardió el flabello, $<$ FLABELLU / nin prisieron de daño cuanto val un cabello; < CAPILLU / solamiente el fumo non se llegó a ello, < I LLL / ni·1 nució más que nuzo yo al bispo don Tello" (Gonzalo de Berceo, Milagros de Nuestra Señora, XIV, 325). En esta misma rima aparece la forma <ello>, cuya grafía $<-11->$ encubría diversas posibilidades articulatorias; así lo constata Lapesa (1985 [1948]: 84) en el caso del Fuero de Avilés: "Esta $l l$ transcribe sin duda el sonido [palatal], de acuerdo con desarrollo fonético de la doble $l$ latina en los romances peninsulares a excepción del gallego-portugués; [...] Otras veces encontramos simple $l$ para $l l$ originaria [...] ela, [...] elos, [...] eles, [...] aquelos [...]; el uso de $l$ con valor de [palatal] abunda en los textos antiguos [...]. Es posible, sin embargo, que en los derivados de ille el escriba no articulase [palatal] sino $l$, ya que en provenzal las formas correspondientes son ela, els, aquels". Contrástese, además, con el mantenimiento de la consonante simple <elo $>$ que presentan los siguientes testimonios peninsulares compuestos en la misma centuria (todos ellos extraídos de la base de datos CORDE): "Ego Farripas adalil \& mea uxor dona Major, metemos nos en Saluatierra conel quinto de quanto que nos auemos de moble \& de raiz, e metemos con elo en el conuent" (Entrada en el convento [Documentos del Reino de Castilla], anónimo, 1210); "\& de fazer cuemo uos quisieredes de elo por que sea a prouecho de buestro monesterio" (Carta de donación [Documentos del Reino de Castilla], anónimo, 1226); "que aconseyedes a estas tres órfanas de suso dichas con elo elo (sic) meyor que uos podierdes" (Testamento [Documentos de la catedral de León], anónimo, 1274); "ela parte que esto non complir peche, a la otra parte que $a$ elo quesier estar, çien morauedis de los nueuos \& ffazer que ffazer" (Carta de donación [Colección Diplomática del Monasterio de Carrizo], anónimo, 1284).

${ }^{31}$ Ms. $O$ : $<$ esperalo $>$; ms. $P$ : $<$ esperarlo $>$. La variabilidad gráfica se hace patente en el mismo manuscrito leonés, en tanto la estrofa anterior ofrece la variante $<$ rll $>$ para $<$ uençerllos $>$, en contraste con la grafía simple $<1>$ de $<$ esperalo $>$ de esta rima. La simplificación es solución compartida por la zona de León, Asturias, Santander y Extremadura (Espinosa Elorza, 2014: 15), pero ¿cómo explicar la variante $<1 \mathrm{l}>$ del mismo manuscrito? ¿Es rasgo influido por el gallego-portugués o, por el contrario, existió variabilidad articulatoria en castellano medieval? Además de aceptar la hipótesis del adstrato gallego, se ha de tener presente la realidad compleja de convivencia de variantes lingüísticas en un mismo diasistema. 
Non ovieron los ángeles razón de vozealla, $<$ der. vOX ca ovo la fin mala e assín fue sin falla; < FALLA tirar no lis podieron valient una agalla, $<$ GALLA ovieron a partirse tristes de la vatalla. < BATTUALIA (Gonzalo de Berceo, Milagros de Nuestra Señora, II, 87).

sangrientas an las barbas, sangrientos los cabellos $<$ CAPILLOS allegavanse muchos por sabor de veellos, < VIDERE + ILLLOS los vnos e los otros morien por acorrellos $<$ CURRERE + $\breve{\text { LLOS }}$


troyana, poesía IV, 37-40).

Sánchez-Prieto Borja (2006: 235), por el contrario, cree poco probable la existencia de una pronunciación geminada reflejada a través del uso de las grafías medievales. Precisamente por ello las rimas revisten importancia en el proceso de reconstrucción del componente fónico de la lengua, ya que son los sonidos, y no las grafías, los elementos que sustentan el proceso de creación poética. Los textos correspondientes a la primera escuela del mester documentan abundantes estrofas con rimas como las aquí recogidas, por lo que no parece posible hablar de casos de asonancia o, incluso, de rimas que justifican la articulación palatal lateral en todos los casos, ya que $<-11->$ encubría distintas articulaciones. Las múltiples posibilidades combinatorias entre el segmento $<\mathrm{rl}>$ $\mathrm{y}<1 \mathrm{l}>$ en los mismos contextos fónicos apuntan tanto al mantenimiento de las dos consonantes originarias, como a una articulación de orden palatal ${ }^{32}$, e incluso otra cercana a la alveolar [1].

\subsubsection{La corte letrada de Alfonso Onceno (1312-1350)}

Las rimas del Libro de Buen Amor revelan seguramente una pronunciación palatal para el resultado de la asimilación entre la vibrante del infinitivo y la lateral del pronombre clítico; sin embargo, no parece improbable admitir, a la luz de los datos aquí expuestos, que estas grafías encubrían una articulación geminada:

(20) Furtava la raposa a su vezina el gallo; < GALLU veíalo el lobo, mandávale dexallo, $<$ LAXARE $+\breve{\text { ILLU }}$ dezié que non devié lo ajeno furtallo ${ }^{33}$. $<$ FURTARE $+\breve{\text { ILLU }}$

${ }^{32}$ En este sentido afirma Lázaro Mora (1979-1980: 268): "El riojano Berceo hizo uso de la asimilación. Y también el autor anónimo del Libro de Apolonio; es cierto que se desconoce su procedencia, pero [...] los rasgos lingüísticos y el tratamiento fonético del texto son absolutamente castellanos".

${ }^{33}$ El ms. S, único que contiene esta estrofa, presenta la lectio $<$ furtarllo $>$, como así lo describen Criado de Val y Naylor (1972: 638): "El copista escribió primero "furtarlo", trazó la segunda 
Él non veyé la ora que estoviesse en tragallo; (Libro de Buen Amor, 321).

El Arcipreste de Hita distingue perfectamente entre la voz gallo, del latín GALLU, y la voz gayo, procedente de GAIU, ya que esta última aparece en rima con voces que presentan pronunciación palatal central [i] (estrofa 1439). Como se ha comprobado, la grafía $<$ ll $>$ de gallo encubría en el reinado de Alfonso Onceno distintos resultados, por lo que en este caso es necesario recurrir a otras rimas para asegurar el contenido fónico subyacente de $<1 \mathrm{ll}$.

(21) Otrossí quando vieres a quien usa con ella $<$ ÍLLA quier sea suyo o non, fáblal por amor della $<$ DE $+\breve{\text { ILLA }}$ si podieres, dal' algo: non le ayas querella $<$ QUERĚLLA, ca estas cosas pueden a la mujer traella. (Libro de Buen Amor, 488).

Se ha constatado en ejemplos anteriores la articulación no palatal de <ll $>$ en rimas compuestas por querella, ella ${ }^{34}$ y candela, por lo que en esta estrofa, la grafía $<1 \mathrm{l}>$ de traella pudo encubrir un sonido geminado, rasgo que se haría extensible al resto de rimantes que contienen esta forma verbal unida al pronombre.

(22) desde oy en siete días, tú e tu almofalla que seades comigo, en campo, a la batalla: < BATTUALIA fasta el Sábado Santo darvos he lit, sin falla; < FALLA de muerte o de lisión non podrás escapalla. (Libro de Buen Amor, 1076).

La voz escapalla, documentada en los testimonios $S$ y $G$, se encuentra en rima con almofalla, procedente del árabe almahala, falla y batalla. Hoy pervive la articulación palatal de [al.mo.'fa.Ka], por lo que esta rima no presenta indicios de que estas formas se pronunciaran con geminada [-1.1-], pese a que no sería pronunciación ajena a esta estrofa.

(23) De quanto que me dixo e de su mala talla < TALĚA fize bien tres cantigas, mas non pud bien pintalla:

las dos son chançonetas, la una de trotalla, de la que no $\mathrm{t}^{`}$ pagares, véyela, ríe e calla $<{ }^{*}$ CALLA (Libro de Buen Amor, 1021)

En principio, el resultado palatal en la voz talla es el esperable a partir de la yod segunda, pronunciación que debería hacerse análoga a las variantes tro-

\footnotetext{
$l$ sobre la $o$ original y añadió otra $o$ ". Esta enmienda, atraída por los imperativos de la rima consonante, adquiere sentido si atendemos a las composiciones de los poetas del cuatrocientos, quienes no hacían coincidir en posición de rima las variantes $<\mathrm{rl}>\mathrm{y}<11>$.

${ }^{34}$ Compárese con su articulación en la estrofa de Berceo (nota 30).
} 
talla y pintalla; sin embargo, si se aceptara la coexistencia de variantes entre la forma geminada y la palatal, no resultaría imposible pensar en una pronunciación alargada [-1.1-] para estas voces.

La siguiente estrofa de Sem Tob reviste importancia por la rima entre $<$ denostalle $>$ y $<$ llamarle $>$. Si aceptamos este caso como tipo de rima homoioteleuton, hemos de atender exclusivamente al segmento átono [-le], por lo que $<$ ll $>$ de $<$ denostalle $>$ no encubría un sonido palatal, sino que el prolongamiento articulatorio del margen implosivo y explosivo de sílaba propició esta rima. Asimismo, en el caso de considerar la rima desde el último acento tónico, resulta de igual modo consonante, en tanto $<\mathrm{ll}>\mathrm{y}<\mathrm{rl}>$ encubrían variantes fónicas cercanas entre sí:

(24) Por end, non puedo cosa loar nin denostalle $35<$ DEHONESTARE ILLI nin dezirle fermosa, sol nin fea llamarle < CLAMARE ILLI (Proverbios morales, 94).

\subsubsection{La corte Trastámara (1351-1454)}

La vigencia de la articulación geminada arroja luz en el proceso de constitutio textus. En la edición de Dutton y González Cuenca (1993) del Cancionero de Baena se duda si el rimante vella de la estrofa de Lope del Monte hace referencia a 'verla' o 'bella':

(25) bueno fuera que pensaran

los que la non dizen vella,

que fuera clara çentella $<$ SCINTILLA

e en todo muy apuesta;

d'otra guisa la su fiesta sería

nuve e non estrella. < STĔLLA (Fray Lope del Monte 324, 16).

En este caso, no haría falta admitir una confusión gráfica en el sistema de labiales ni una pronunciación palatal como solución exclusiva; es decir, el mantenimiento de la articulación geminada (o palatal) en la forma verbal ver unida al pronombre clítico la, en convivencia con las soluciones palatales del resto de voces en rima, dota al verso de sentido completo: 'sería bueno que aquellos que dicen no verla piensen que es en todo apuesta', en lugar de 'sería bueno que aquellos que no le dicen bella piensen que es en todo apuesta'. Con ello, además de coherencia semántica, se obtiene regularidad en la rima consonante.

${ }^{35}$ El testimonio $C$, considerado por la crítica como el más fidedigno, y $M$ ofrecen las variantes $<$ denostalle $>$ y $<$ denostalla $>$, respectivamente; en tanto $E$ y $N$, copiados a mediados del siglo XIV y durante la primera mitad del XV, prefieren $<$ denostar la $>$ y $<$ desloar la $>$. En cambio, para el segundo verso, $C$ opta por $<$ llamarle $>$ y $M N$ por $<$ llamarla $>$. 
La grafía <-ll-> de batalla encubría, asimismo, tanto una palatal lateral, como una articulación geminada, descripción que refuerza la siguiente rima de Alfonso de Baena con <otealla>:

(26) E assí concluyendo, gentil cavalgante, sostengo contrario de aquesta batalla: < BATTUALIA que nunca se vençe por mucho otealla ninguna fermosa sin ser demandante. (Juan Alfonso de Baena 371, 2).

La articulación de contrallos 'contrarios', seguramente cercana, bien a la de una líquida lateral alveolar simple por un proceso de disimilación o trueque consonántico $^{36}$ ([kon.'tra.rjo] $>*$ [kon.'tra.ljo] $>*$ [kon.'tra.lo]), bien a la de una palatal ([kon.'tra.rjo] $>*$ [kon.'tra.ljo] $>*[$ kon.'tra.Ko]), debe hacerse extensible a las formas verbales de infinitivo con pronombre clítico en las siguientes estrofas de Juan Alfonso de Baena:

(27) levantáronse en christianismo

contra él tantos contrallos, < CONTRARIOOS

que non podrían contallos

por la cuenta de alguarismo. (Juan Alfonso de Baena 586, 99).

Pues de todos es contrallo, $<$ CONTRARIO

no dexallo

$[\ldots]$

dar tras él hasta matallo.

Bien corrido como gallo $<$ GALLU

yo lo hallo, < FALLO

$[\ldots]$

quando tiene luego dallo,

él es causa de hallallo. (Juan Alfonso de Baena 588, 15).

De igual modo, la variabilidad gráfica entre $<-$-rl- $>$ y $<-11->$, documentada en los manuscritos del Rimado de Palacio, es muestra de esta convivencia de variantes:

${ }^{36}$ Sin embargo, para Corominas y Pascual (2006-2007 [1980-1991]: s. v. contra) no sería ejemplo de articulación geminada, ya que: "es frecuente en el s. XV la variante contrallo (J. Manuel, J. Ruiz, Sem Tob, en rima en los Canc. de Stúñiga y de Baena), debida a una base disimilada contralio", por ello, Corominas y Pascual afirman que la forma <contrales> de Juan Manuel (contrales la una de la otra) no es correcta; sin embargo, esta solución gráfica, contrastada con las formas en posición de rima, es válida, en tanto $<1>$ encubría una articulación líquida lateral, palatal o geminada. La siguiente estrofa de Gómez Manrique constata convivencia de formas, en este caso, frente a la estrofa de Juan Alfonso de Baena, la variante palatal es resultado esperado para la rima con bitualla y encalla: "Cuál será la bitüalla, < VICTUALİ / para que bien naveguemos / y cuando la fusta encalla < INCALLAT / o el tiempo nos contralla, 'contraria' / si es bien soltar los remos" (Gómez Manrique 73, 37-41). 
(28) El su governalle es nuestro prelado; (Rimado de Palacio, 829b).

Son escuros de pensallos nin saber dellos un tanto? (ms. E: <pensar los>) (Rimado de Palacio, 1339c).

Aunque non sea tan justo tenerlo en grant honor (Rimado de Palacio, $1613 b)$.

En esta misma línea, Rafael Lapesa afirma, acerca de un verso de Macías del poema Pues mi triste coraçón, que

todo es castellano menos un quere[l]e en vez de querelle; pero este querele, por otra parte, asegura con la rima la autenticidad del castellano consuele, pues el gallego console no habría podido consonar con querele. Es preciso admitir que Macías se propuso valerse del castellano [...]; pero tal propósito no bastó para que evitase la $l$ gallega de querele en lugar de la $l l$ castellana (Lapesa, 1985 [1953]: 243-244).

Comparto la opinión de Lapesa en aceptar que la rima de los versos de Macías es totalmente castellana; sin embargo, la pronunciación [-1-] de [ke.'re.le] podría no ser lusismo, en tanto la articulación prolongada [ke.'rel.le] rimaría en consonancia con [kon.'swe.le]. El estudio de las rimas de los poetas, en la misma línea que Lapesa, permite aclarar este tipo de interrogantes en el proceso de reconstrucción lingüística.

Las composiciones de los poetas de la corte Trastámara aragonesa constatan articulación no palatal de voces con $<11>$, en rima consonante con la estructura de infinitivo y pronombre clítico $<\mathrm{rl}>$. Es el caso de las coplas sobre las cualidades de las mujeres hechas por Pedro Torrellas, catalán de nacimiento y primer poeta cortesano bilingüe (Beltran, 2009a: 446):

(29) Mas, del vicio embevecidos, creen los hombres en ellas: < ILLLAS

¡Oh cuitados, decebidos, que los más andáis vendidos e pasáis sin conocerlas! (Pedro Torrellas 114, 86-90).

Sin embargo, las rimas perfectamente compuestas por Suero de Ribera revelan articulación palatal, o incluso geminada, tanto en el poema que censura los malos cortesanos, como en el dezir a él atribuido:

(30) el galán flaco, amarillo < AMARĔLLU

ha de ser e muy cortés, rasonar bien del arnés mas non curar de vestillo, cavalgar trotón morsillo < MAURICĚLLU

o faca rucia rodada, 
nunca en el freno barvada, el manto corto e sensillo. < *SINGĔLLU (Suero de Ribera 116, 25-32).

Yo, con voluntad muy presta, me llegué a conoscellas; començó la una de ellas < ÍLLAS esta canción tan honesta: (Suero de Ribera 118, 5-8).

La rigurosidad con la que estos poetas componían sus estrofas, muchas de ellas destinadas a la realeza, es rasgo compartido que impide considerar la asonancia como recurso poético; además, aceptar la rima entre ellas y conocerlas de Pedro Torrellas como asonante, supondría una afirmación inadecuada, en tanto sería la única estrofa de todo el poema en el que se da dicha forma de rima.

La lírica castellana de la corte Trastámara encuentra sus orígenes en la tradición poética galaico-portuguesa, así lo demuestran las primeras composiciones recogidas en el Cancionero de Baena, e incluso en el cruce interlingǘ́stico documentado en el poema del rey Alfonso Onceno "En un tiempo cogí flores"37. Si bien esta influencia pudo haber sido el motor desencadenante de la generalización con la variante palatal de los infinitivos con pronombre (Espinosa Elorza, 2014), el contraste que ofrece las rimas del mester de clerezía apunta a que la influencia de la escuela poética occidental motivó la regularización de los rimantes; en otras palabras, desde las primeras composiciones se constata la coexistencia de la forma simple lateral [1] y geminada lateral [1.1], soluciones propias de la lengua, y la articulación palatal, seguramente prestada del galaico-portugués, en un momento de fuerte influencia métrico-estilística (Gómez Redondo, 2016). Todas ellas conviven de manera heterogénea a lo largo de los testimonios de los textos poéticos hasta las colecciones cancioneriles, momento en que los poetas tienden a crear, como norma general, rimas homogéneas consonantes entre $<\mathrm{ll}>([-1.1-] /[-\Lambda-])$, por un lado, $\mathrm{y}<\mathrm{rl}>([-\mathrm{r} .1-])$, por otro.

\subsubsection{Enrique IV (1454-1474)-los Reyes Católicos (1474-1504)}

Las rimas de esta época revelan que, en caso de pervivir la articulación geminada, habría sido de manera exclusiva en contextos de fonética sintáctica y sandhi externo, tales como la articulación de los infinitivos con pronombre clítico, rasgo conservado hasta nuestros días en el Mediodía español:

${ }^{37}$ Sirvan los siguientes versos para demostrar la fuerte influencia galaico-portuguesa en las composiciones de base castellana: "¿Que é de aquesta mi senhora / que mucho desejo haver?" (Alfonso Onceno, 11-12). 
(31) como en claros miralles,

[...]

trabajad por resemblalles. (Gómez Manrique 39, 7-10).

Pues no aprovecha templalla

ni por ello mejor suena,

por no estar en esta pena,

muy mejor será quebralla

que pensar hazella buena. (Jorge Manrique 22, 5-9).

como quien caça por valles, < VALLES

$[\ldots]$

yo faré por no faltalles. (Gómez Manrique 39, 37-40).

con esta carne rebusta,

para bien o mal passalle ${ }^{38}$,

Dios nos dio manera justa:

la libertad es la fusta,

la razón, el governalle. (Pedro de Cartagena 150, 25-29).

La rima entre miralles y resemblalles de Gómez Manrique y la compuesta por Jorge Manrique entre templalla y quebralla son muestras de la generalización de la variante palatal o geminada de estas formas de infinitivo con pronombre, frente a la que conservó las dos consonantes líquidas sin disimilar. La articulación prolongada lateral habría convivido con la solución palatalizada, realidad que habría hecho posible la rima consonántica con valles, en la estrofa de Gómez Manrique, o governalle, en el caso de Pedro de Cartagena. Así pues, estas voces podrían haberse pronunciado bien con la consonante palatal lateral (['ba.Kes], [go.ßer.'na.Ke]), bien con la geminada (['bal.les], [go.ßer.'nal.le]), a la luz de las rimas de los poetas castellanos medievales, desde el reinado de Fernando III hasta el ocaso del gobierno de los Reyes Católicos.

En esta misma línea, las rimas de Juan del Enzina, Garci Sánchez de Badajoz y Diego de San Pedro también revelan mantenimiento de la articulación geminada o palatal:

(32) de Dios que quiso levalla, aunque el Evangelio calla, < CALLAT (Juan del Enzina La fiesta de la Asunción, 65-66).

es querer poder hazello,

[...]

de los santos un cabello! < CAPÍLLU (Juan del Enzina La fiesta de la Asunción, 582-585).

\footnotetext{
${ }^{38} \mathrm{La}$ rima con < governalle> confirma el empleo de /le/ en lugar de /lo/ y, por tanto, la confusión leísta por parte del autor.
} 
Tu victoria es contemplalla, sin penar por mereçella, vee que goçaras en vella, la gloria de la batalla, libre del peligro della, < DE ÍLLA (Garci Sánchez de Badajoz 40, 31-35).

No era allí menester la fuerça que en la batalla $<$ BATTUALIA suele el capitán poner al tiempo ya del romper para bien acabdillalla, (Diego de San Pedro, La passion trobada, 13).

Por el bien que siento en vella deuo yo a dios alabança del tengo tambien querella $<$ QUERELLA porque de mi mal andança fue causador en hazella Pero fue tal marauilla $<$ MIRABILIA ser de tan excellente ser que he por bueno su nacer y aun el mio por seruilla (Garci Sánchez de Badajoz 78, 10-18).

Las rimas de Juan del Enzina y Diego de San Pedro demuestran la pervivencia de la variante palatal para estas formas verbales en rima con calla, cabello y batalla. Sin embargo, de igual modo que la grafía inicial $<\mathrm{l}>$ de $<$ levalla $>$ pudo articularse como alveolar lateral o palatal, la grafía doble $<11>$ también encubría una pronunciación no palatal, como es el caso de $<$ excellente $>$ del verso 16 de Garci Sánchez de Badajoz. Este dato no permite asegurar la pronunciación palatal lateral para los rimantes de la estrofa de este poeta, ya que el proceso de asimilación pudo desembocar en una variante articulatoria geminada.

Las siguientes rimas de Gómez Manrique, Juan del Enzina y Diego de San Pedro apoyan la idea de que existió la variante que mantenía la secuencia [-r.l-] del infinitivo con pronombre clítico. Esta es la forma que se habría mantenido junto a la articulación geminada o palatal que terminó desapareciendo en la zona septentrional de la Península en favor de la variante más etimológica, compuesta por las dos consonantes líquidas:

(33) nin se goza por averlos, nin sospira por perderlos. (Gómez Manrique 56, 1217-1218).

nuestras fuerças en servirle, [...] no cessemos de seguirle. (Juan del Enzina La fiesta de la Resurrección, 177-180). 
Él siempre en esta porfía
rehusando de matarlo,
los judíos todavía
como la imbidia crescía
no cessavan de acusarlo. (Diego de San Pedro, La passion trobada, 136).

La poesía de la corte de los Reyes Católicos refuerza la teoría que aquí presentamos: la influencia de la poesía galaico-portuguesa en la andadura de la tradición cancioneril castellana motivó la regularización en posición de rima de las variantes articulatorias procedentes de la asimilación de infinitivo y pronombre. La forma etimológica que presentaba mantenimiento de las dos consonantes líquidas no desapareció, pero no parecía ser la forma preferida por los poetas, en contraste con aquella representada con la grafía doble $<$ ll $>$, que encubría, al mismo tiempo, una articulación palatal o geminada lateral ${ }^{39}$.

\section{CONCLUSIONES Y PROPUESTA TEÓRICA A LA LUZ DE LAS RIMAS DE LOS POETAS}

La división entre los fenómenos fonéticos acaecidos en interior de palabra y aquellos correspondientes a los de fonética sintáctica, o sandhi externo, permite obtener resultados más específicos en torno al cambio lingüístico; es el caso de la existencia de dos tipos de articulaciones geminadas en castellano medieval, esto es, la que pervivió como reducto de la antigua geminada latina en posición intervocálica y la originada por la asimilación de dos consonantes líquidas en las formas verbales de infinitivo y pronombre clítico. Así lo ha puesto de manifiesto el análisis de las rimas consonantes de los poetas medievales que aquí presentamos, en tanto forman parte de composiciones cultas con una clara tendencia a la rima regular perfecta:

i. El segmento latino geminado -LL- palatalizó desde muy temprano en romance castellano; sin embargo, son varios los indicios que permiten suponer la existencia de una articulación geminada etimológica, seguramente vinculada a la lengua más culta. Así lo demuestran tanto las rimas del mester de clerezía (Libro de Alexandre, entre mala, batalla, falla y tavla; Libro de Buen Amor,

${ }^{39}$ De igual modo que la grafía $<\mathrm{f}>$ se empleaba, según el análisis de la métrica del verso, para representar un sonido fricativo sordo, una aspiración, e incluso [Ø] (Pla Colomer, 2014a y en prensa). La convivencia de formas presentes en las rimas también fue subrayada por Lázaro Mora (1979-1980: 274-275): "La palatalización o no del grupo brindaba a los escritores una doble opción, con posibles finalidades caracterizadoras. En algunos se observa una preferencia por $l l$, sobre todo cuando componen poemas villanescos o desenfadados; pero estamos hablando sólo de una preferencia. Ese hecho no parece más que una tendencia que no puede constituirse en ley, entre otras razones, porque los poetas cultos del arte mayor también emplearon $l l$; aunque bien es verdad, en proporciones menores". 
entre candela, ella, centella y querella; Libro de miseria de omne, entre mortales, valles, piñascales y males; y la rima interna de Sem Tob entre querellas y rrebellas), como las de los poemas de cancionero (Ruy Páez de Ribera, entre fable y calle; Juan de Mena, entre Sçilla y quadrilla; y el Marqués de Santillana, entre suelo, Bello, buelo y assuelo).

A pesar de que no abundan los ejemplos en el corpus seleccionado, parecen ser suficientes para ver en las rimas de todos ellos una aproximación fónica entre el segmento palatal lateral y una articulación lateral no palatalizada. Este modo de componer rimas consonantes no debió ser rasgo privativo de una escuela poética en concreto, en tanto se documenta en estrofas de versos de arte mayor y de arte menor, todos ellos relacionados con el ámbito culto. En esta línea, la rima de Sánchez de Badajoz en lengua castellana y latina es reveladora, ya que muestra cómo se articulaba el segmento latino geminado; no es de extrañar que este aprendizaje culto motivara la creación de rimas entre una consonante alveolar lateral simple y una articulación geminada. Seguramente, lo que era rasgo lingüístico obsoleto, pasó al ámbito poético como reducto lingüístico que permitía a los poetas regularizar las rimas hasta que este rasgo, en sí minoritario, cayó en desuso en el reinado de Enrique IV.

Desde el punto de vista gráfico, por tanto, la grafía doble <-11-> encubría distintos valores fónicos:

- palatal lateral $\left(\left[-\Lambda^{-}\right]\right)$, constituyente fonológico de la lengua castellana,

- simple alveolar lateral ([-1-]), como cultismo gráfico. Es el caso de $<$ mill $>$,

- geminada alveolar lateral ([-1.1-]), reducto fónico que actuaría a modo de alófono de la palatal lateral en los casos en que el hablante era consciente de recuperar la pronunciación latina más culta.

ii. Desde las primeras composiciones poéticas en lengua castellana se constata convivencia de variantes para las formas de infinitivo y pronombre clítico:

- mantenimiento de las líquidas etimológicas ([-r.l-]), acorde con las leyes fónicas que hacen referencia a la fuerza de las consonantes en dicha posición: las líquidas laterales, con más fuerza que las líquidas vibrantes, ocupan el margen explosivo de sílaba, mientras que las vibrantes se mantienen en el margen implosivo de la misma,

- asimilación de las líquidas en un sonido geminado ([-r.l-] > [-1.1-]), como se constata en la rima homoioteleuton de Sem Tob entre denostalle y llamarle, en tanto los datos expuestos no parecen apoyar la evolución del tipo $[-\mathrm{r} .1-]>[-\Lambda-]$.

La variante palatal, como afirma Espinosa Elorza (2014), fue préstamo lingüístico que se vio reforzado por la introducción de la poesía cancioneril de raigambre galaico-portuguesa, hecho que produjo un reajuste en la composición de las rimas y su consecuente regularización entre los segmentos que conserva- 
ban las líquidas sin disimilar, por un lado, y aquellos que mantenían la palatal heredada o la geminada patrimonial, por otro. Muchas de las rimas analizadas apuntan a que la grafía $<11>$, para estos casos, encubría una articulación palatal; sin embargo, la documentación del mismo tipo de voces en posición de rima, sobre todo en la poesía del cuatrocientos, imposibilita asegurar, a ciencia cierta, el contenido fónico subyacente de dicha grafía.

La variante palatal, vigente en los textos poéticos hasta el siglo XVII, se ha mantenido como vulgarismo en algunas zonas del Mediodía peninsular, registrada hasta la segunda mitad del siglo XVI en América (Espinosa Elorza, 2014: 22); a partir del reinado de los Austria su uso decae a favor de la forma etimológica que presenta las dos consonantes líquidas etimológicas, conservada desde los albores de la lengua castellana.

\section{CORPUS}

Alvar, Manuel (ed.) (1976): Libro de Apolonio (Estudios, edición, concordancia), Madrid, Fundación Castalia/Fundación March.

Beltran, Vicenç (2009a): Edad Media: lírica y cancioneros, Madrid, Visor Libros.

Beltran, Vicenç (ed.) (2009b): Poesía cortesana (siglo XV), Madrid, Biblioteca Castro.

Beltran, Vicenç (ed.) (2013): Poesía de Jorge Manrique, Madrid, Real Academia Española/Galaxia Gutenberg.

Casas Rigall, Juan (ed.) (2007): Libro de Alexandre, Madrid, Castalia.

Castillo, Julia (ed.) (1980): Cancionero de Garci Sánchez de Badajoz, Madrid, Editora Nacional.

CORDE = Real Academia Española: Banco de datos (CORDE) [en línea]. Corpus diacrónico del español. $<\mathrm{http}: / / \mathrm{www} \cdot \mathrm{rae} . \mathrm{es}>$.

Corominas, Juan (ed.) (1967): Libro de Buen Amor, Madrid, Gredos.

Criado de Val, Manuel y Eric W. Naylor (eds.) (1972): Libro de Buen Amor, Madrid, CSIC.

Cuesta Serrano, Jaime (ed.) (2012): Libro de miseria de omne, Madrid, Cátedra.

Díaz-Mas, Paloma y Carlos Mota (eds.) (1998): Sem Tob de Carrión, Proverbios morales, Madrid, Cátedra.

Dutton, Brian y Joaquín González Cuenca (eds.) (1993): Cancionero de Juan Alfonso de Baena, Madrid, Visor Libros.

Gómez Moreno, Ángel y Maximilian P. A. M. Kerkhof (eds.) (1988): Marqués de Santillana. Obras completas, Barcelona, Planeta.

Gómez Moreno, Ángel y Teresa Jiménez Calvente (eds.) (1994): Las obras de Juan de Mena con anotaciones del Brocense, Madrid, Biblioteca Castro.

González Llubera, Ignacio (ed.) (1947): Santob de Carrión, Proverbios morales, Cambridge, University of Cambridge.

Kerkhof, Maximilian P. A. M. (ed.) (1995): Laberinto de Fortuna, Madrid, Castalia.

Lapesa, Rafael (ed.) (2010): Rimado de Palacio. Esbozo de edición crítica por Rafael Lapesa Melgar con la colaboración de Pilar Lago, prólogo y estudio introductorio a cargo de Giuseppe Di Stefano, Valencia, Generalitat Valenciana/Consellería de Cultura i Esport/Biblioteca Valenciana.

Menéndez Pidal, Ramón (1976): Textos medievales españoles. Obras completas de R. Menéndez Pidal, XII, Madrid, Espasa-Calpe. 
Pérez Priego, Miguel Ángel (ed.) (1989): Juan de Mena. Obras completas, Barcelona, Planeta. Pérez Priego, Miguel Ángel (ed.) (1996): Juan del Encina. Obra completa, Madrid, Biblioteca Castro.

Real Academia Española (ed.) (1989): Cancionero de Juan del Encina: primera edición, 1496, publicado en facsímil, Madrid, Real Academia Española.

Severin, Dorothy S. y Keith Whinnom (eds.) (1979): Diego de San Pedro. Obras completas, III. Poesías, Madrid, Castalia.

Uría, Isabel (coord.) (1992): Gonzalo de Berceo. Obra Completa, Madrid, Espasa-Calpe/Gobierno de la Rioja.

Weiss, Julian y Antonio Cortijo Ocaña (eds.) (2015): Glosa sobre las Trezientas del famoso poeta Juan de Mena, Madrid, Ediciones Polifemo.

\section{BIBLIOGRAFÍA}

Alarcos Llorach, Emilio (1951) "La lengua de los «Proverbios morales» de don Sem Tob", Revista de Filología Española, XXXV, 1, pp. 249-309.

Alarcos Llorach, Emilio (1965): "Representaciones gráficas del lenguaje", Archivum, 15, pp. 5-58.

Alarcos Llorach, Emilio (1981): "De algunas palatales leonesas y castellanas", en Eugenio Coseriu, Horst Geckeler y Wolf Dietrich (eds.), Logos Semantikos. Studia linguistica in honorem Eugenio Coseriu, Madrid/Berlín, Walter de Gruyter/Gredos, vol. 5, pp. 267-276.



Alonso, Amado (1969-1976 [1955]): De la pronunciación medieval a la moderna en español, Rafael Lapesa (ed.), Madrid, Gredos.

Alonso, Dámaso (1972 [1962]): “Temas y problemas de la fragmentación fonética peninsular", en Dámaso Alonso, Obras completas, I: Estudios lingüísticos peninsulares, Madrid, Gredos, pp. 13-291.

Ariza Viguera, Manuel (1994): Sobre fonética histórica del español, Madrid, Arco/libros.

Ariza Viguera, Manuel (2009): La lengua del siglo XII (dialectos centrales), Madrid, Arco/libros.

Ariza Viguera, Manuel (2012): Fonología y fonética históricas del español, Madrid, Arco/libros.

Cano Aguilar, Rafael (1988): El español a través de los tiempos, Madrid, Arco/Libros.

Catalán, Diego (1989 [1971]): "En torno a la estructura silábica del español de ayer y del español de mañana”, en Diego Catalán, El español. Orígenes de su diversidad, Madrid, Paraninfo, pp. 77-104.

Corominas, Juan y José Antonio Pascual (2006-2007 [1980-1991]): Diccionario Crítico Etimológico Castellano e Hispánico, Madrid, Gredos.

Corral Checa, M. ${ }^{a}$ Antonia (1992): "Una aportación más a los estudios de las grafías que contendían en los albores del Renacimiento", en Manuel Ariza, Josefa M. ${ }^{a}$ Mendoza, Rafael Cano y Antonio Narbona (eds.), Actas del II congreso internacional de historia de la lengua española, I, Madrid, Pabellón de España, pp. 225-235.

Echenique Elizondo, M. ${ }^{a}$ Teresa (2013): "Fuentes y vías metodológicas para el estudio de la pronunciación castellana a través de su historia. De Amado Alonso al siglo XXI", en M. ${ }^{a}$ Teresa Echenique y Fco. Javier Satorre (eds.), Historia de la pronunciación de la lengua castellana, Valencia/Neuchâtel, Tirant lo Blanch/Université de Neuchâtel, pp. 29-60.

Echenique Elizondo, M. ${ }^{\text {a }}$ Teresa y M. ${ }^{a}$ José Martínez Alcalde (2013): Diacronía y gramática histórica de la lengua española, 5. ${ }^{a}$ edición revisada y aumentada, Valencia, Tirant humanidades.

Echenique Elizondo, M. ${ }^{a}$ Teresa y Francisco P. Pla Colomer (2013): "Reconstrucción fonética y periodización a la luz de la métrica y la rima", en M. Teresa Echenique y Fco. Javier Satorre (eds.), Historia de la pronunciación de la lengua castellana, Valencia/Neuchâtel, Tirant lo Blanch/Université de Neuchâtel, pp. 63-106. 
Espinosa Elorza, Rosa María (2014): "Lo que la $l l$ esconde", en José Luis Ramírez Luengo y Eva Patricia Velásquez Upegui (eds.), La historia del español hoy. Estudios y perspectivas, Lugo, Axac, pp. 11-25.

Gómez Redondo, Fernando (1998): Historia de la prosa medieval castellana, Madrid, Cátedra.

Gómez Redondo, Fernando (coord.) (2016): Historia de la métrica medieval castellana, en colaboración con Carlos Alvar, Vicenç Beltran y Elena González-Blanco García, San Millán de la Cogolla, Cilengua.

Lapesa, Rafael (1981): Historia de la lengua española, 9. ${ }^{a}$ ed. corregida y aumentada, Madrid, Gredos.

Lapesa, Rafael (1985 [1948]): “Asturiano y provenzal en el Fuero de Avilés”, en Rafael Lapesa, Estudios de historia lingüística española, Madrid, Paraninfo, pp. 53-122.

Lapesa, Rafael (1985 [1953]): "La lengua de la poesía lírica desde Macías hasta Villasandino”, en Rafael Lapesa, Estudios de historia lingüística española, Madrid, Paraninfo, pp. 239-248.

Lázaro Mora, Fernando (1979-1980): "RL $>l l$ en la lengua literaria", Revista de Filología Española, 60, pp. 267-283.

Lloyd, Paul (1993): Del latín al español. I. Fonología y morfología históricas de la lengua española, Madrid, Gredos.

Marcet, Vicente (2006): El sistema consonántico del leonés: Peculiaridades fonéticas y usos gráficos en la documentación notarial del siglo XIII, Salamanca, Universidad de Salamanca.

Marcet, Vicente (2007): "Lengua y escritura en la Edad Media: la representación de consonantes palatales en la documentación notarial leonesa", Anuario de Letras: Lingüística y filología, 45 , pp. 5-23.

Marcet, Vicente (2008): "La sustitución de los usos gráficos leoneses por los castellanos en la representación de [y] <-LY a lo largo del siglo XIII. Nueva aproximación", Res Diachronicae, 6, pp. 73-85.

Menéndez Pidal, Ramón (1941): Manual de gramática histórica española, 6. ${ }^{a}$ ed., Madrid, Espasa-Calpe.

Menéndez Pidal, Ramón (1960): "Dos problemas iniciales relativos a los romances hispánicos", en Manuel Alvar, Antonio Badía, Rafael de Balbín y Luis F. Lindley Cintra (dirs.), Enciclopedia lingüística hispánica, Madrid, CSIC, vol. I, pp. XXVII-CXXXVIII.

Montenegro Duque, Ángel (1960): “Toponimia latina”, en Manuel Alvar, Antonio Badía, Rafael de Balbín y Luis F. Lindley Cintra (dirs.), Enciclopedia lingüística hispánica, Madrid, CSIC, vol. I, pp. 501-530.

Narbona Jiménez, Antonio, Rafael Cano Aguilar y Ramón Morillo-Velarde Pérez (2011): El español hablado en Andalucía, Sevilla, Universidad de Sevilla.

$N T L L E=$ Real Academia Española: Nuevo Tesoro Lexicográfico de la Lengua Española, $<\mathrm{http} /$ /ntlle.rae.es/ntlle/SrvltGUILoginNtlle>.

Penny, Ralph (2005 [2004]): "Evolución lingüística en la Baja Edad Media: evoluciones en el plano fonético", en Rafael Cano (coord.), Historia de la lengua española, Barcelona, Ariel, pp. 593-612.

Penny, Ralph (2006 [1993]): Gramática histórica del español, 2.. ed., Barcelona, Ariel.

Pensado, Carmen (1993): "Consonantes geminadas en la evolución histórica del español", en Ralph Penny (ed.), Actas del primer congreso anglo-hispánico. Tomo I: Lingüística, Madrid, Castalia, pp. 193-204.

Pla Colomer, Francisco Pedro (2014a): Letra y voz de los poetas en la Edad Media castellana. Estudio filológico integral, Valencia/Neuchâtel, Tirant humanidades.

Pla Colomer, Francisco Pedro (2014b): "Letra y voz de Ayala: canciller entre tradición y vanguardia", Revista de Historia de la Lengua Española, 8, pp. 113-148.

Pla Colomer, Francisco Pedro (2015a): "Mester es que las palabras sepa bien silabificar. Estudio filológico del Libro de miseria de omne", Rivista di Filologia e Letterature Ispaniche, 18, pp. 9-42. 
Pla Colomer, Francisco Pedro (2015b): "Métrica y pronunciación en el Libro de Buen Amor: prototipo del isosilabismo castellano medieval", Analecta Malacitana, 38, pp. 55-78.

Pla Colomer, Francisco Pedro (2018): "Por que escritura rimada es mejor decorada. Nueva revisión sobre la lengua, métrica y estilística de los Proverbios morales de Sem Tob", Rilce. Revista de Filología Hispánica, 34 (1), pp. 312-339.

Pla Colomer, Francisco Pedro (en prensa): "Aportaciones a la evolución castellana de F- latina en su contexto románico: del signo lingüístico al signo poético", Zeitschrift fur Romanische Philologie.

Ruiz García, Elisa (2004): Los libros de Isabel la Católica. Arqueología de un patrimonio escrito, Salamanca, Instituto de Historia del Libro y de la Lectura.

Sánchez-Prieto Borja, Pedro (2006): "Interpretación fonemática de las grafías medievales", en José Jesús de Bustos Tovar y José Luis Girón Alconchel (eds.): Actas del VI Congreso Internacional de Historia de la Lengua Española, Madrid, Arco/Libros, vol. I, pp. 219-260.

Torreblanca, Máximo (1982-1983): "La geminación de $l$ y $n$ latinas en el dialecto mozárabe", $L a$ Corónica, 11, pp. 300-306.

Tuten, Donald N., Enrique Pato y Ora. R. Schwarzwald (2016): "Spanish, Astur-Leonese, Navarro-Aragonese, Judaeo-Spanish", en Adam Ledgeway y Martin Maiden (eds.), The Oxford Guide to the Romance Languages, Oxford, University Press, pp. 382-410.

Veiga, Alexandre (2009 [1997]): "La geminación consonántica en latín clásico: realidad fonética y análisis fonológico", en Alexandre Veiga, El componente fónico de la lengua. Estudios fonológicos, Lugo, Axac, pp. 239-258.

Veiga, Alexandre (2009 [2000]): "Del fonema castellano /j/", en Alexandre Veiga, El componente fónico de la lengua. Estudios fonológicos, Lugo, Axac, pp. 273-312.

Zampaulo, André (2014): "Los cambios diacrónicos de la lateral palatal en la historia del castellano: evidencia cronológica, comparativa y dialectal para una nueva propuesta", Revista de Historia de la Lengua Española, 8, pp. 149-174.

Fecha de recepción: 14 de diciembre de 2016

Fecha de aceptación: 2 de febrero de 2017 